\title{
Paisaje y Arquitectura renacentista en el valle del Guadalquivir: El Puente de Ariza (Úbeda)
}

José Martínez Peñarroya *

\section{Introducción}

Presentamos en el siguiente estudio una visión retrospectiva de la arquitectura y la ingeniería históricas en España, centrada en un monumento que no por desconocido deja de ser atrayente, máxime cuando sus condiciones de conservación hace que se halle en serio peligro de desaparición completa.

Arquitectura e ingeniería anteriores a nuestro siglo no significa ni ruina ni atraso, sino simplemente $y$ en muchas ocasiones desconocimiento de una realidad fragmentada. Cientos de infraestructuras y estructuras se hallan diseminadas por campos e inmediaciones de nuestras ciudades, sin que conozcamos en muchas ocasiones ni su origen ni su historia. Las grandes obras, las que han perdurado al tiempo y sus avatares, tanto por la importancia que tuvieron en su día y que las mantuvieron en uso -y no hemos de repetir ejemplos de todos conocidos, como el acueducto de Segovia o el puente de Alcántara-, son realmente escasas, aunque en la mayoría de las ocasiones sí representativas. De distinta manera se nos presentan los miles de edificios, puentes, vías y demás ejemplos de la arquitectura y la ingeniería anteriores al siglo $X X$, de los que, además del emplazamiento y los materiales, poco mas conocemos.

Proyectos puntuales nos refrescan la memoria de algunas estructuras; otros sistemáticos, los menos, encuentran memoria en determinados aspectos del pasado. Pero no suelen ser lo suficientemente completos para esbozar visiones de conjunto o necesarias síntesis. No podemos pedir que se estudie y sistematice la totalidad de los restos arquitectónicos existentes, sino que cada día las labores sean mas coordinadas, exista información suficiente sobre las mismas y que dispongamos de las medidas mas urgentes para atender a la conservación de los significativos y de la difusión de los prototípicos. La estructura es el puente de Ariza, construido en el siglo $\mathrm{XVI}$, para salvar un vado del río Guadalimar, ejemplo aislado de los miles que podríamos traer a estas páginas. Paisaje y Arquitectura de los pasados siglos que se nos hacen presentes al posar nuestra vista en la superficie de unos muros que tienen algo mas que muchos años.

\section{Paisaje}

El Puente de Ariza o de las Navas cruza el río Guadalimar en dirección Norte-Sur, en una zona de topografía escasamente abrupta, aunque muy variada y dinámica. En general, la litología del entorno corresponde a materiales del Secundario (Triásico y Lías Jurásico) y Terciarios (Tortoniense y Andaluciense Miocénicos). La cobertera cuaternaria aportada por el río es totalmente holocénica, presentando escasa extensión y potencia en la zona del puente. El

* Licenciado en Prehistoria y Arqueología 
roquedo más cercano está compuesto por aluviones arenosos con finos y grava de variada granulometría, irregularmente rodada, que se apoyan sobre un sustrato de areniscas y arcillas que aflora en las zonas de apoyo de la estructura. Por encima de ellos, sobre todo en la margen izquierda del río, mucho más abrupta, se instala un potente paquete dolomítico, que define el frente de cuesta de la llamada Loma de Úbeda. Hacia el Norte, en la margen derecha del río, las areniscas del Buntsandstein, fuertemente falladas, son recubiertas en zonas alejadas del área de estudio por la misma cobertera Jurásica.

El tapiz vegetal de la zona se reduce a una extensa mancha de olivos, cultivo predominante, y a una estrecha franja de bosque galería que se conserva parcialmente en las cercanías del puente. Se constata la presencia de álamos negros, chopos y lentiscos y en las zonas más elevadas, alejadas del cauce, especies degenerativas de Quercus, alternándose con un piso inferior de arbustos y plantas de ribera. Todas estas características producen un entorno de ubicación de la estructura, especialmente sugerente, al agruparse diversas especies silvestres en sus cercanías, lo que contrasta con las amplias extensiones olivareras.

El emplazamiento exacto del puente de Ariza es la coordenada UTM 30 SVH 468025 42। 8556, que tradicionalmente se puede expresar como los 38 06' 52" latitud Norte y los

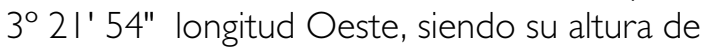
$332 \mathrm{~m}$. en el punto de altura máxima sobre la clave del arco mayor. Se encuentra ubicado en la hoja número 906 del Mapa Topográfico Nacional a escala 1:50.000, denominación "Úbeda".

\section{Antecedentes históricos}

Aunque pueda parecer extraño en una obra de tal importancia, la investigación histórica sobre el Puente de Ariza ha ofrecido escasos resultados. La consulta en bibliotecas de organismos estatales (Biblioteca Nacional, Ministerio de Obras Públicas y Urbanismo, Museo Arqueológico Nacional, Consejo Superior de Investigaciones Científicas y archivos de cartografía histórica) sólo ha sido capaz de ofrecer una serie de datos sueltos, cortas citas inconexas que definen claramente el estado de la investigación sobre algunas obras civiles en España.

La obra más completa sobre puentes antiguos en nuestro país (Fernández Troyano, 1985) ni siquiera lo cita, aunque nos consta personalmente su alto nivel de conocimiento actual acerca de dicha estructura. La revista del Ministerio de Obras Públicas, en su número monográfico sobre los puentes de España, lo cita entre los andaluces del siglo XV al XVII y le dedica poco más de diez líneas '. Unicamente poseemos otra cita actual acerca de nuestro puente; (Almendral 1982) ${ }^{2}$. Similar carencia documental a la comentada por Almendral ha podido ser constatada por nosotros, siendo la falta de información casi absoluta, siendo la única cita que hemos podido recoger anterior a nuestro siglo, la contenida en el Diccionario Histórico de Pascual Madoz (1844) ${ }^{3}$.

\footnotetext{
I "Aún en vida de Carlos V, el obispo de Jaén, Don Diego de los Cobos y Molina, mandó hacer un puente para comunicar la loma de Ubeda con Sierra Morena y con Castilla, saltando sobre el Guadalimar. Es el puente de Ariza, hecho entre I550 y I560. Otra prenda renacentista de suavísimo alomamiento, apenas perceptible, y gran luz central que salva el río. Arco principal con desembocadura de doble rosca y casi treinta y dos metros de luz.". En esta cita, aparte de una serie de errores en cuanto a la filiación y cronología dada a la obra, se deja entrever la superficialidad de la investigación llevada a cabo, al omitirse las diferentes remodelaciones y considerar que un puente con un marcado lomo de asno en su fase inicial, presenta un "suavísimo alomamiento".

2 "... de aquellas fechas [Reconquista] conservamos en Jaén algunos caminos y sus puentes, y entre éstos, especialmente el Puente de Ariza, que está en servicio entre Úbeda y Arquillos". Continúa la cita exponiendo algunas de las caracerísticas del puente, como que se trata de uno de los puentes más bellos de la provincia. Sus características fundamentales son la existencia de un gran arco central de medio punto, con treinta y dos metros de luz, unas rampas pronunciadas y cuatro pequeños arcos laterales. La longitud ddel mismo es de noventa y nueve metros, siendo su fábrica de sillería de roca ródeno (arenisca). Y continúa textualmente: "Aunque parezca raro, no es monumento nacional y es poco conocido; nosotros no hemos encontrado antecedentes documentales de este puente, llamado también de El Milagro, por alusión a uno de S. Juan de la Cruz. Lo dataríamos en el siglo XVI, con una modificación en el XIX".

3 En el tomo correspondiente a Jaén, voz Guadalimar: “...en el Trm. de las Navas [...] por fin, dist. I/2 leg. se encuentra el famoso Puente Nuevo o de las Navas."
} 
Si analizamos sobre un mapa topográfico actual el antiguo término de Las Navas y los restos de caminos y cañadas ganaderas que, desde este municipio llegan al término de Úbeda, encontramos que el "famoso Puente Nuevo o de las Navas" no era otro que el puente de Ariza, y el camino de las Navas a Úbeda, abandonado por el trazado de la carretera actual, una parte del Real de Toledo a Almería.

El puente es omitido sistemáticamente en los numerosos libros de viajes escritos a lo largo de los siglos XVIII y XIX, por viajeros españoles y extranjeros, en consonancia con el abandono y decaimiento de las regiones de Levante y Andalucía Oriental, en beneficio de los centros andaluces occidentales, catalizadores del comercio de las Indias. Este fenómeno de basculamiento de los centros comerciales merece ser comentado en detalle para entender cómo una obra de la importancia de la estudiada ha pasado por nuestra historia prácticamente desapercibida. El aparato burocrático y militar de las monarquías inmediatamente posteriores a la Reconquista, se basaba, sobre todo en la colaboración de los grandes señores provinciales, en mayor medida cuanto más alejados se encontraban éstos de los centros de poder. Su control implicaba el mantenimiento de privilegios y prebendas para aquellos que, de hecho, les permitían actuar como pequeños monarcas en sus dominios. El marco más favorable para el beneficio económico y social de estos auténticos grupos de poder, vinculados con frecuencia a las casas reales por lazos de parentesco o servidumbre funcionarial, se basaba en la explotación ganadera transhumante, para lo que resultaba indispensable el mantenimiento de unas rutas más o menos estables y seguras.

El gran auge de este modelo económico, en detrimento de los productores agrícolas, fue una de las causas principales de enriquecimiento de la ciudad de Úbeda, que, en consonancia con la monumentalidad y riqueza de su casco urbano, es capaz de sufragar, como veremos más adelante, la construcción íntegra de un puente de las características del estudiado.
Todavía en la actualidad, el análisis de los mapas topográficos en uso, permite apreciar la gran densidad de vías pecuarias existente dentro del término ubetense, en el que confluían dos importantísimas cañadas; una procedente del Norte, que es la que utiliza el Puente de Ariza y otra que, en dirección Sudoeste-Nordeste, enlazaba esta zona de las Sierras Prebéticas con Levante, manteniendo un esquema de comunicaciones vital para la economía de este área desde la época de la conquista romana. El decaimiento de los mecanismos productores del sector primario en los siglos entre el descubrimiento de América y la pérdida de las colonias, implica el paulatino abandono de toda ruta de tráfico que no estuviese orientada al comercio ultramarino atlántico, fenómeno que afecta tan fuertemente a la comarca de Úbeda y en general a las zonas del centro Sur continental de la Península que es entonces cuando se acuña la expresión de "andar por los cerros de Úbeda", para definir a quien anda al margen de las realidades económicas y sociales al uso.

\section{Antecedentes cartográficos}

Al tener una idea más o menos precisa de la fecha de construcción del puente, centramos nuestra búsqueda cartográfica en publicaciones en torno a la mitad del siglo XVI y posteriores, siendo los siguientes los principales mapas localizados y los resultados obtenidos. En el repertorio de Villuga (1543) se observa que para llegar hasta Úbeda desde el Norte, hay que llegar hasta Vilches $y$, desde allí, atravesar el río por un puente de barcas, posiblemente a la altura del Azud de los Escuderos. Arquillos, en este momento, no pasa de ser una venta o posada en el camino de Albacete a Córdoba, sin comunicación directa con Úbeda. No aparece otra forma de cruce del Guadalimar que el citado puente de barcas. Posteriormente en la Descripción del Reino de Jaén de Salcedo de Aguirre, (1617) presenta una línea de puntos entre Úbeda, Mármol y Puente Nueva, siguiendo entre Arquillos y Las Navas. También aparece Puente Vieja. Se trata de un mapa muy impreciso en la ubicación de elementos, pero en la zona al Norte de Úbeda pueden apre- 
ciarse dos puentes, sobre un río que pudiera ser el Guadalimar, identificando el situado más al Norte con el puente de Ariza.

En época posterior contamos con el mapa realizado por Tomás López (1787), en el que no aparece ningún camino pero sí la referencia a Puente Nueva (sobre el Guadalimar) y aguas abajo la Puente Mocha o Vieja, que serían, con toda probabilidad, los restos del antiguo puente de barcas en el camino de Vilches a Úbeda, citado por Villuga. Por último en el mapa ya de nuestro siglo de Benito Chías aparece ya como Puente de Ariza, mostrando un trazado de caminos idéntico al Mapa de la Diócesis de Jaén de 1887.

Las conclusiones que pueden obtenerse del análisis cartográfico inciden nuevamente en el olvido en el que había caído la comarca. La importancia del puente como obra en sí, mantiene su recuerdo en la toponimia y en las representaciones cartográficas, pero la ruta Norte Sur, desviada hacia el Oeste por la creciente importancia de los puertos de Sevilla y Cádiz, hace que la red viaria de esta zona desaparezca paulatinamente.

\section{Antecedentes documentales}

La gran cantidad de información sobre el puente localizada en los archivos municipales de Úbeda, contrasta con su ausencia en otras fuentes documentales. De todas formas, la imposibilidad de consultar la gran cantidad de documentos puestos a nuestra disposición por los responsables del mismo, nos obliga a hacer un breve resumen de los datos obtenidos.

La primera mención que se hace de la construcción de un puente sobre el Guadalimar es del primer cuarto del siglo XVI, para la comunicación definitiva de Úbeda y Baeza con una zona denominada Las Correderas; con seguridad, algún lugar en el entorno del paso de Despeñaperros. El proyecto de construcción se encarga con posterioridad al famoso arquitecto Andrés de Vandelvira (Alcaraz I509- Jaén 1575), autor entre otras obras de la Catedral de Jaén, y es el Concejo de Úbeda y no el
Obispo de los Cobos el que, no sólo encarga la obra, sino quien la sufraga en su práctica totalidad. La primera fase de obras se inicia en torno a $15 \mid 2$, construyéndose un arco del puente con arenisca local.

Con posterioridad, existe un vacío de información y no hay nuevas noticias hasta mediados de siglo, cuando se contratan canteros y aprovisionamiento de piedra de mejor calidad, pues la que se había utilizado resultaba inadecuada para la construcción. Este es el proyecto que realiza el arquitecto Vandelvira. Este breve episodio puede explicar, tal vez en conjunción con una modificación natural del curso del río, la presencia del extraño arco, sumamente erosionado, que encontramos bajo uno de los arcos medianos del puente.

Es, pues, a mediados del siglo XVI, en donde se puede documentar el acopio de materiales, contratación de personal, etc. para el inicio de la obra definitiva que atravesará por varias vicisitudes, debidas sobre todo a la falta de fondos y que se hallan perfectamente registradas en los archivos consultados. Baste decir, como anécdota que, para finalizar la obra, el Concejo ubetense tuvo que encarcelar al maestro cantero y a toda su cuadrilla, obligándoles a trabajar en régimen de forzados, al negarse los obreros a continuar en tanto no se les abonasen las cantidades adeudadas por el Concejo. Finalmente, se da como fecha de final de obra la del año | 583. También es posible seguir las sucesivas reformas efectuadas en el pasado, siendo la principal de ellas la rectificación de rasantes realizada en 1847, debido a las quejas de los carreteros por la elevada pendiente de las rampas de acceso que provocaban el atasque de los pesados carros de la época.

Acerca de Andrés de Vandelvira, podemos decir que se trata del arquitecto de Úbeda por excelencia. Nacido en Alcaraz en I509, comienza a trabajar como cantero en Uclés en I530. Muy pronto (I536), lo veremos dirigiendo los trabajos de construcción de la iglesia-capilla de El Salvador, en Úbeda. Fuertemente influenciado por el arquitecto Machuca en su sentido riguroso del Clasicismo, dota a sus obras de una característica sobriedad que se irá desvane- 
ciendo con el paso de los años. El período más fértil de su carrera como proyectista y constructor se dividirá entre Jaén, en donde se le localiza en 1564 durante las obras de la Catedral Nueva, pero sobre todo en Úbeda y en los pueblos de su entorno (Canena, VillacarriIlo, Baeza), donde realiza gran cantidad de obras entre 1536 y 1570, período que se ajusta a la perfección, salvo en su fase final, con la construcción del puente de Ariza, que él no verá terminado, ya que fallece en Jaén (I575), ocho años antes de la conclusión de las obras del mismo en 1583.

\section{Descripción de la estructura}

Es un puente en lomo de asno, totalmente construido en piedra arenisca, procedente de canteras ligeramente alejadas de la zona (área de Vilches posiblemente), con cinco arcos de medio punto, todos ellos de diferente luz, si bien el conjunto posee una marcada simetría sobre un plano vertical que coincide con la clave del arco mayor, situado en posición central. Tanto los arcos citados como los conjuntos de pilares y contrafuertes son diferentes, al menos en su métrica. El material constructivo es una piedra arenisca de grano fino y escasa dureza, tallada en sillarejo de bloques no isodómicos (irregulares), pero conservando en todos los casos forma paralelepípica. El módulo medio de tamaño es un bloque cuadrangular de $42 \times 20 \times 35 \mathrm{~cm}$. Toda la estructura se halla trabada con una mezcla de mortero de cal con abundante arena e inclusiones cerámicas de aporte muy pequeñas.

El estado general de conservación es bueno, aunque el arco central presenta los riñones ligeramente hundidos, con algunas dovelas sueltas en estas zonas. Casi todos los lienzos hacia el exterior se encuentran repellados con cemento moderno, aplicado sin ningún cuidado, lo que deteriora la visión en detalle de la estructura.

Los arcos, de medio punto, disminuyen en anchura y altura desde el central (32 m.) notablemente más grande, siguiendo la línea del pretil inclinado que define una estructura gene- ral en lomo de asno, con el ápice sobre la clave del arco central. Los pilares del puente se asientan sobre basamentos de hormigón con cantos rodados y abundante cal. A este mismo basamento corresponde un arco, también en piedra arenisca, con claras señales de escorrentía de agua tanto por encima como por su interior, cuya parte superior, sensiblemente horizontal, crea una plataforma bajo uno de los arcos medianos del puente. Su luz es ligeramente inferior a la del arco que sobre él se apoya. Está formado por dovelas de gran longitud, irregulares y muy desgastadas por el agua. Dichas dovelas están cubiertas por el tipo de hormigón ya descrito, regularizando la plataforma superior, a la que se accede por un pasaje en codo al que se entra por la fachada Oeste del segundo pilar sobre la margen izquierda del río, saliendo bajo el arco superior por su parte central.

El puente original ha visto modificado su aspecto por una rectificación de rasantes realizada en el siglo XIX, para eliminar la fuerte pendiente de las rampas originales y que está formada por dos cuñas de mampostería trabadas con argamasa, con sus vértices sobre la clave del arco central y una altura superior a los cuatro metros sobre ambos arranques del puente. Sobre ellas se emplaza una cornisa corrida a ambos lados del puente con vuelo sobre la vertical de los paramentos. No es posible saber por el momento, al carecer de representaciones y descripciones antiguas, si dicha cornisa correspondería a la fase más antigua y fue reaprovechada. Ya en la segunda mitad de este siglo, se le añaden dos largos taludes con recubrimiento exterior de mampostería llagueada, realizados al plantearse el actual trazado de la carretera que tiene dos importantes curvas de entrada y salida al puente, en contraste con el camino original, completamente recto.

Las medidas básicas de la fase inicial del puente son: una longitud máxima de $95 \mathrm{~m}$., altura máxima de $17 \mathrm{~m}$. y una luz del arco principal de $32 \mathrm{~m}$. El aspecto general es de sobriedad, con paramentos lisos, salvo por una moldura corrida que recorre ambos paramentos exteriores, bordeando y rodeando arcos y con- 
trafuertes respectivamente. Además el único elemento escultórico es un altorrelieve, muy erosionado, en forma de medallón que se esculpe directamente sobre las tres dovelas centrales de la fachada Oeste del arco mediano en la margen izquierda del río, junto a la puerta de entrada hacia el pasaje en codo.

Disgregado por elementos estructurales, el puente consta de los siguientes elementos:

- Dos pilares de arranque con contrafuertes cuadrangulares a ambos lados.

- Dos arcos pequeños en los extremos del puente.

- Dos pilares de sección rectangular, con contrafuertes cuadrados a ambos lados.

- Dos arcos medianos, entre los arcos pequeños y el central.

- Un arco, probablemente más antiguo, bajo uno de estos arcos medianos, en la margen izquierda del río.

- Dos grandes contrafuertes de apoyo al arco central. El de la margen izquierda presenta planta en punta de ángulo recto aguas arriba y semicircular aguas abajo. El de la margen derecha es completamente irregular. Desarrollado sobre una base cuadrangular en la parte más alejada del lecho del río, se transforma en dos largos tajamares, completamente excéntricos con respecto a un ángulo teórico de $90^{\circ}$ perpendicular al eje longitudinal del puente.

- Un gran arco central de medio punto, con doble rosca de dovelas y $32 \mathrm{~m}$. de luz.

Se describe a continuación cada elemento por separado, desde el Sur hacia el Norte. El pilar núm. I es el primer elemento de asiento de la estructura. Engancha, más o menos en vertical, con algunos engatillados, con la rampa moderna de acceso en curva. Sobre él el añadido de mampostería del siglo XIX, alcanza su mayor espesor (más de 4,50 m.). Posee contrafuertes de planta rectangular, simétricos a ambos lados, con coronamiento en cubierta inclinada a un agua. En su base no puede apre- ciarse el tipo de cimentación al estar cubierta por coluviones de ladera. En ambos paramentos, la moldura que recorre el puente bordea en horizontal los contrafuertes.

En el arco núm. I observamos que tampoco puede verse el basamento en el interior de éste al estar lleno de agua. Bien terminado hasta donde puede llegar a verse, la escasa altura sobre el suelo de la línea de impostas le da un aspecto suavemente peraltado, aunque se trata de un verdadero medio punto. La línea de impostas viene marcada por una pequeña zarpa, coincidente con los salmeres, ligeramente sobresalientes. Las dovelas son bastante regulares, sin resaltarse la clave, característica común al resto de los arcos. La rosca del arco es de unos $55 \mathrm{~cm}$. Por el exterior de ambos paramentos, la línea de trasdós aparece recorrida en todo su desarrollo por la moldura corrida que llega al arco por encima de la segunda dovela, a contar desde el salmer.

El pilar núm. 2 puede dividirse en dos niveles. El primero, más elevado, tiene planta cuadrangular, estando su base más o menos a la misma altura que el pilar I. En ambas fachadas presenta contrafuertes de sección plantar cuadrangular, con remate en cubierta inclinada a un agua. Estos contrafuertes son sensiblemente más anchos y altos que los adosados al pilar I. Con excepción de la moldura y una pequeña zarpa, ya iniciada en el arco I a menos de un metro de la base, que recorren las fachadas de la estructura, incluyendo los contrafuertes, presenta paramentos lisos. A partir de la línea de impostas, bastante baja en este caso, el pilar soporta un pequeño tímpano.

El nivel inferior de este pilar, hacia el segundo arco y el cauce, es bastante más complicado. En primer lugar, presenta un desarrollo en altura mucho mayor para adaptarse a la topografía de la vaguada, manteniendo la altura de la línea de impostas, definida por la mima pequeña zarpa que veíamos en el arco I. Inmediatamente bajo esta zarpa está la plataforma que define la parte superior del antiguo arco, que se presenta a primera vista como un elemento ajeno por completo al puente. 
En la fachada Oeste, aguas abajo, el pilar presenta en posición central una puerta $(1,89$ $\times 92 \mathrm{~cm}$.), con un arco de medio punto formado por tres elementos, con un curioso enganche en doble cola de milano. Dicha puerta, remarcada además por una elevación de la moldura exterior permite acceder a un pasaje por el interior del pilar, formado por dos tramos rectos unidos a $90^{\circ}$. Presentan paramentos verticales de sillarejo cuidado, cubiertos con bóveda de cañón. La salida de este pasaje se hace por el interior del segundo arco, ligeramente hacia el Oeste del eje longitudinal del puente mediante una puerta, también de medio punto, que permite acceder a la plataforma sobre el trasdós del arco inferior y que sigue perfectamente la curvatura interior del arco.

A una cota inferior al nivel de suelo de los dos primeros arcos, encontramos un encaje o tajamar de grandes dimensiones en ambos lados de la estructura. Dicho tajamar, con más de ocho metros de lado en ambos casos, ofrece un paramento vertical hacia el lado del cauce, que termina en una gran zarpa que se adelgaza hasta desaparecer en el extremo exterior del tajamar. Por su parte inferior, en contacto con el suelo, esta zarpa posee un paramento vertical, de pequeña altura que comienza a ras de los salmeres del antiguo arco inferior, aunque por su factura, materiales y estado de conservación corresponde a la fase principal del puente.

El arco núm. 2 tiene una luz ligeramente superior a los nueve metros $(9,02)$, tiene dovelas de disposición radial, ligeramente recortadas en cuña, cuidadas aunque no completamente regulares, con una rosca en torno a los ochenta centímetros, apoyándose sobre salmeres ligeramente sobresalientes. A simple vista, siete de estas dovelas se encuentran partidas y repelladas con cemento recientemente. En la fachada Oeste, la clave y las dos dovelas a ambos lados de ésta se encuentran adornadas con un altorrelieve de forma circular que representa a una figura antropomorfa alada, con atributos que debido al mal estado de conservación no han podido ser identificados. Es la única representación figurada que se encuentra en todo el puente.
Directamente bajo este arco, con su misma anchura, y una luz sensiblemente menor (7,70 m.) aparece el extraño arco inferior, construido en otro tipo de piedra arenisca mucho más blanda, completamente desgastado por la circulación del agua tanto por encima como por debajo del arco. Aunque parece una obra ajena al conjunto del puente, una detallada inspección de su enganche con la estructura principal, revela que los sillares que forman sus salmeres y algunas dovelas que se enjarjarían en los pilares a sus lados, están talladas en ángulo, formando a la vez parte de arco y pilar. De ello puede deducirse que, si bien este elemento parece ser más antiguo que el conjunto completo, no puede serlo en exceso, ya que en su construcción se prevé el encaje en otra obra mayor. Opinamos que puede tratase del primer elemento realizado en un proyecto inicial que, debido a la mala calidad de los materiales utilizados, su escaso aforo y, posiblemente, una migración lateral del lecho del río, que se despega de la base de la cuesta hasta su actual posición, deja sin servicio a este arco por lo que, inmediatamente, ha de modificarse el proyecto.

El elemento sustentante más regular de todos es el pilar número 3. Está formado por un módulo prácticamente cuadrado de $6,20 \mathrm{~m}$ de lado al que se une, aguas arriba un tajamar en cuña regular, con ángulo central en $90^{\circ}$ y 4,44 m. de lado. Aguas abajo el tajamar tiene planta semicircular, siendo el diámetro igual a 6,10 m. Es completamente regular y liso en su desarrollo vertical, excepción hecha de la moldura corrida y de una pequeña zarpa en su tercio inferior. Está coronado por un sombrerete sin voladizo, que puede haber sufrido modificaciones durante la rectificación de rasantes del siglo XIX.

El elemento constructivo más característico del puente es el arco central o número 3, de medio punto, muy regular, a pesar de hallarse ligeramente desplomado en ambos riñones. Su principal característica es hallarse construido mediante una doble rosca, con dos hileras de dovelas concéntricas de diferente tamaño que van a morir a los pilares de ambos lados, enjarjándose hasta la rasante en ellos a la altu- 
ra de la línea de impostas. A partir de ésta las primeras nueve dovelas, enjarjadas en profundidad, son horizontales, seguramente para mejorar la posición de la línea de presiones, lo que da a este arco un ángulo aproximado de $124^{\circ}$, muy cercano a los $120^{\circ}$ considerados como ángulo ideal para mejorar la capacidad de carga de un elemento de este tipo (Fernández Troyano 1985). Sobre la novena dovela se asienta una en forma de cuña pronunciada, que equivaldría a un auténtico salmer. A partir de él, todas las dovelas, incluida la clave, son rectangulares para ambas roscas, con una rosca total de $1,60 \mathrm{~m}$.

La primera rosca, interior, es más ancha que la situada por su trasdós, siendo sus dovelas más grandes. Muchas de éstas están partidas. El arco, de medio punto, se presenta ligeramente abierto en las zonas de enjarje. Esto, unido a la baja posición de la línea de impostas, le da aspecto de arco rebajado, aunque las medidas de su flecha (I5,80 m.) y su luz (32 m.) lo definen como un semicírculo casi perfecto. La moldura que originalmente llega desde los pilares a este arco a bastante altura, se ve complementada por un tramo de características similares que, recorriendo también el trasdós de la rosca externa, llega hasta los pilares.

En la base del arco hay una serie de elementos extraños al mismo. En su lado Sur, presenta un agujero circular, tapado cuidadosamente con un cilindro de piedra de su mismo diámetro. Este círculo queda definido por los lados tangentes de dos grandes sillares que han sido tallados ex profeso para adoptar esta forma circular. En la parte Norte y ligeramente sobre la línea de impostas, hay cinco grupos, regularmente distribuidos sobre la horizontal, de tres grandes sillares enjarjados en la pared interna del arco, con sus lados interiores cuidadosamente alisados y el exterior sin desbastar. Cada grupo de tres piedras define un seno de forma cuadrangular abierto por arriba. Esto nos hace pensar que pudiera tratarse de los apoyos originales de la cimbra, que faltan en el lado contrario. Con respecto a la abertura circular y a su tapa de piedra, no tenemos idea alguna sobre su función, a no ser que se trate de un desagüe para drenaje interno de la estructura.
El pilar 4, de altura similar al pilar 3, en el resto de sus características es completamente diferente. Se sitúa en el extremo Norte del arco principal que se enjarja profundamente en aquél. El núcleo de su planta es rectangular, con un eje longitudinal de 8,90 m. Esta sección se ve profundamente alterada con la adición de dos largos tajamares en el lado correspondiente al arco central, emplazados irregularmente. La cara del tajamar situada aguas arriba ofrece a la corriente un ángulo de incidencia mayor que el de salida. Esto se consigue desplazando el eje longitudinal de los tajamares unos $10^{\circ}$ en sentido contrario al giro de las agujas del reloj, con respecto a la perpendicular con el eje longitudinal de la estructura.

En vertical, los tajamares se transforman mediante un achaflanado oblicuo en contrafuertes de planta trapezoidal escalena, siendo diferentes entre sí. Ambos contrafuertes están rematados por sombreretes en forma de casquete redondeado, a la misma altura que el pilar 3.

El arco núm. 4 tiene una luz de 8,25 m. y repite al detalle las características del arco 2. Está formado por 42 dovelas a cada paramento, con salmeres ligeramente sobresalientes, bastante regulares y de $0,80 \mathrm{~m}$. de rosca. En su parte superior y lado Norte se encuentra recorrido en el trasdós por la moldura corrida. El pilar número 5 tiene una planta básica rectangular, de 5, I0 ×6,20 m., con contrafuertes de planta cuadrangular a ambos lados, similares a los de los pilares I y 2 . Presenta una pequeña zarpa en todo su perímetro, coincidiendo con la línea de impostas de los arcos 4 y 5 . Todo el conjunto se asienta sobre un basamento de hormigón, claramente visible en todo su perímetro, que se apoya directamente sobre la roca arenisca de fondo.

El arco número 5 es idéntico a su contrario, al otro lado del puente, con una luz ligeramente mayor $(6,42 \mathrm{~m}$.). El arco tiene 33 dovelas, con salmeres poco destacados y una rosca de 0,55 m. La línea de impostas viene marcada por una pequeña zarpa. El trasdós se halla recorrido, en toda su longitud, a partir de la tercera dovela por moldura corrida. El pilar número 6 es el último elemento del puente. 
Similar al situado en el otro extremo, carece de zarpa, presentando paramentos lisos en pilar y contrafuertes, excepción hecha de la omnipresente moldura. Engancha prácticamente en vertical con el talud de acceso, aunque existen elementos en la misma que pueden ser sillarejos antiguos reaprovechados.

\section{Conclusiones}

A partir de los datos obtenidos pueden ofrecerse las siguientes conclusiones de tipo histórico: La construcción del puente aparece perfectamente documentada en una fecha, para la fase principal del mismo, sobre los inicios de la segunda mitad del siglo XVI, estando bien documentados sus plazos de realización y su conclusión en 1583.

El proyecto original corresponde a un conocido arquitecto de la época; Andrés de Vandelvira, entre cuyas obras destacan varias realizadas en la misma provincia de Jaén y en la misma época. El puente en sí es un hermoso ejemplo de obra civil renacentista, carácter que se acentúa al poder documentarse claramente el alcance de las diferentes remodelaciones efectuadas. Ninguna de las obras realizadas sobre la estructura con posterioridad al siglo XVI, posee valor histórico o cultural alguno. Existen en dicho puente elementos tales como los tajamares asimétricos, el pasaje en codo, los grandes encajes de ribera, etc., que hacen de él un ejemplo único de ingeniería civil de comienzos de la Edad Moderna. La estructura se halla en muy buenas condiciones de conservación, careciendo de modificaciones irreversibles.

No quisiéramos que el final de nuestras conclusiones fuera solamente un canto lamentable sobre el estado de los restos arquitectónicos de los edificios y las obras de ingeniería de los pasados siglos. La multitud de la obra viva, los innumerables ejemplos que mantenemos y que nos hacen la vida mas agradable, a la par que nos hacen detenernos momentáneamente y reflexionar en el discurrir diario en tiempos pasados. Los edificios civiles, las iglesias, los puentes, las puertas y las murallas de las ciudades son los ejemplos más vivos y más cercanos que tienen la virtud de retrotraernos instantáneamente a esos momentos.

Pero la labor fragmentaria, el día a día de las labores de documentación y divulgación, y en ocasiones de descubrimiento de aspectos inéditos sobre un lugar bien conocido, es una tarea poco conocida, pero no menos agradecida, patente en proyectos como el descrito en las líneas precedentes, en los que los restos de edificios, obras de ingeniería y, en fin, manifestaciones de patrimonio edificado son el centro sobre el que gira nuestro trabajo.

Pero no estamos solos, y la historia se escribe cada día por más personas y por más equipos de investigación, que se unen en el camino de sintetizar y explicar lo que para muchos hasta hace poco no era más que un montón de piedras. Señal de los tiempos de cambio, señal de una población que siente suyos la tierra hecha casa y la piedra hecha monumento, en el paisaje heredado y que transmitimos a nuestros herederos, enriquecido con el nuevo bagaje de patrimonio edificado que cada época se encarga de conducir a buen puerto.

\section{BIBLIOGRAFÍA}

ALMENDRAL, J. M. (1982), Jaén desde sus Obras Públicas. Colec. de Ciencias, Humanidades e Ingeniería, n²4, Pp. 77, Madrid

ALZOLA Y MINONDO, P. de (1979), Las Obras Públicas en España: Estudio Histórico, Colegio de Ingenieros de Caminos, Canales y Puertos, Madrid.

ARENAS DE PABLO, J.J. (1982), El Puente, pieza esencial del mundo humanizado. Santander.

CHUECA GOITIA, F. (1953), "Arquitectura del siglo XVI", Ars Hispaniae, Vol. II, Madrid.

CHUECA GOITIA, F. (1965), Historia de la Arquitectura española. Madrid, 1965.

CHUECA GOITIA, F. (197I), Andrés de Vandelvira, arquitecto. Inst. de Estudios Giennenses, Jaén.

FERNANDEZ CASADO, C. (1950), Breve historia de las Obras Públicas en España. Madrid.

FERNANDEZ TROYANO, L. (1985), "El Patrimonio Histórico de las Obras Públicas y su conservación: Los Puentes". Rev. Informes de la Construcción, n 375, Madrid 
MADOZ, P. ( I 845), Diccionario Geográfico-Estadístico-Histórico de España y de sus posesiones de Ultramar. T. 9, Pp. 19, Madrid. (Puente de Ariza)

MADRAZO MADRAZO, S. (1984) El sistema de comunicaciones en España. 1750 - 1850. Madrid

MINISTERIO DE CULTURA (1973-1980), Inventario del Patrimonio Arqueológico y Artístico de España. Madrid.

MINISTERIO DE OBRAS PUBLICAS Y URBANISMO (1987), "Guía de los Puentes de España". Rev. MOPU, nº 345, Madrid.

MINISTERIO DE OBRAS PUBLICAS Y URBANISMO (1990), "Guía de los ríos de España". Rev. MOPU, n 378 Madrid

\section{Cartografía Histórica}

CHIAS, Benito (1912), Mapa de la provincia de Jaén, Editorial Martín, Barcelona.

SALCEDO DE AGUIRRE, Gaspar (1617) Descripción del Reino de Jaén Ordenada por el Dotor Gaspar Salcedo de Aguirre, natural de Baeza y Prior de Arjonilla.

LOPEZ, TOMAS (1787), Mapa Geográfico del Reyno de Jaén, Madrid.

VILLUGA, PERO JUAN (I546). Repertorio de todos los Caminos de España

SERVICIO HISTORICO DEL EJÉRCITO, plano núm. 2683

SERVICIO HISTORICO DEL EJÉRCITO, plano núm. 2688

\section{Cartografía temática}

\begin{tabular}{|llcccc|}
\hline Clase & Editor & Nombre & Número & Fecha & Escala \\
\hline Topográfico & Serv. Geog. Ejército & Ubeda & 906 & 1.977 & $1: 50.000$ \\
\hline Topográfico & Inst. Geográfico Nal. & Ubeda & 906 & 1.901 & $1: 50.000$ \\
\hline Topográfico & Serv. Geog. Ejército & Ubeda & 906 & 1.968 & $1: 50.000$ \\
\hline $\begin{array}{l}\text { Cultivos y } \\
\text { Aprovecham. }\end{array}$ & $\begin{array}{l}\text { Ministerio de } \\
\text { Agricultura, P. y A. }\end{array}$ & Ubeda & 906 & 1.977 & $1: 50.000$ \\
\hline Geológico & Inst. Geo. Min. España & Ubeda & 906 & 1.977 & $1: 50.000$ \\
\hline
\end{tabular}




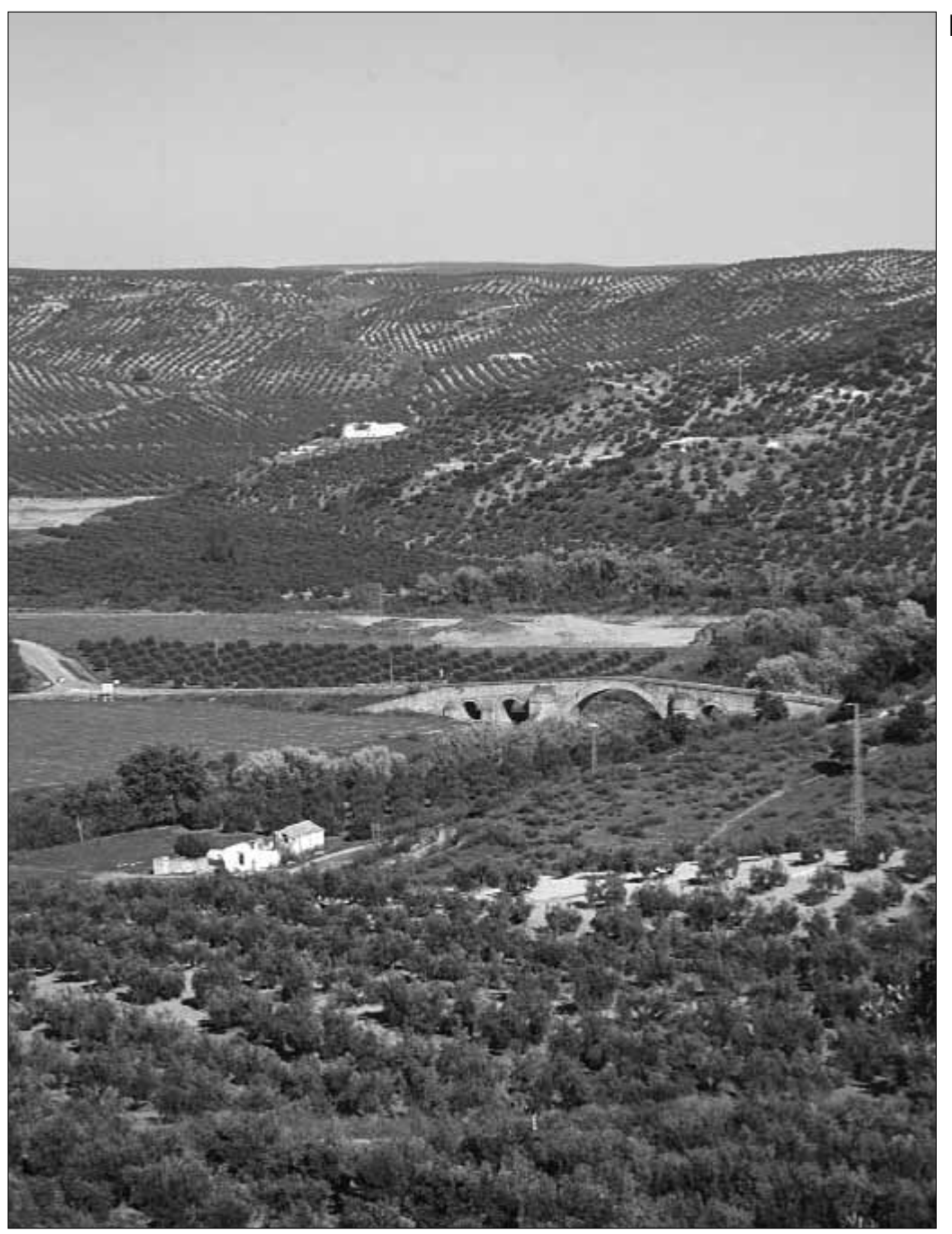

Fig. I. Emplazamiento del puente de Ariza desde el Sudoeste.

Fig. 2. El puente de Ariza desde el Noroeste.

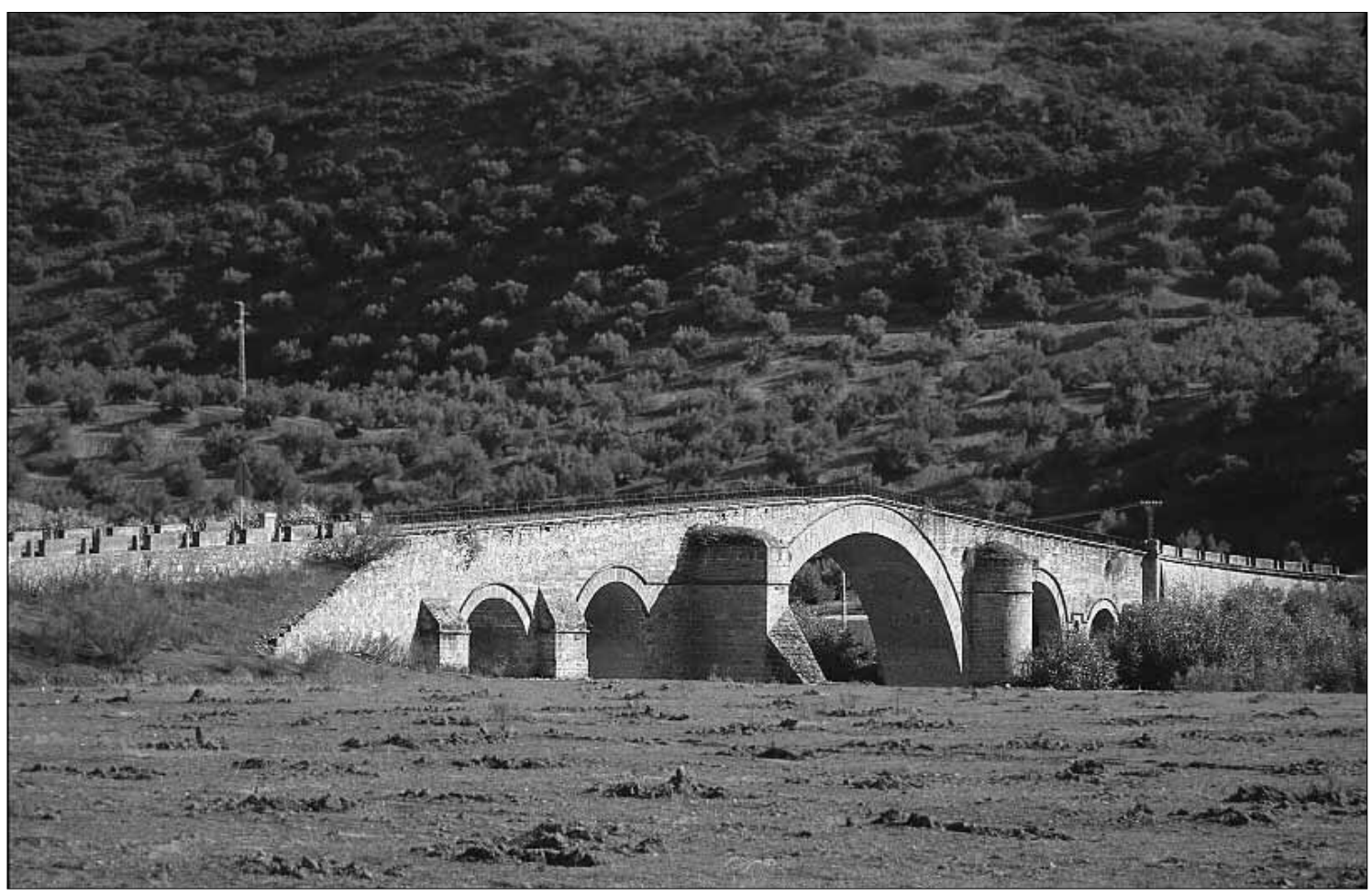




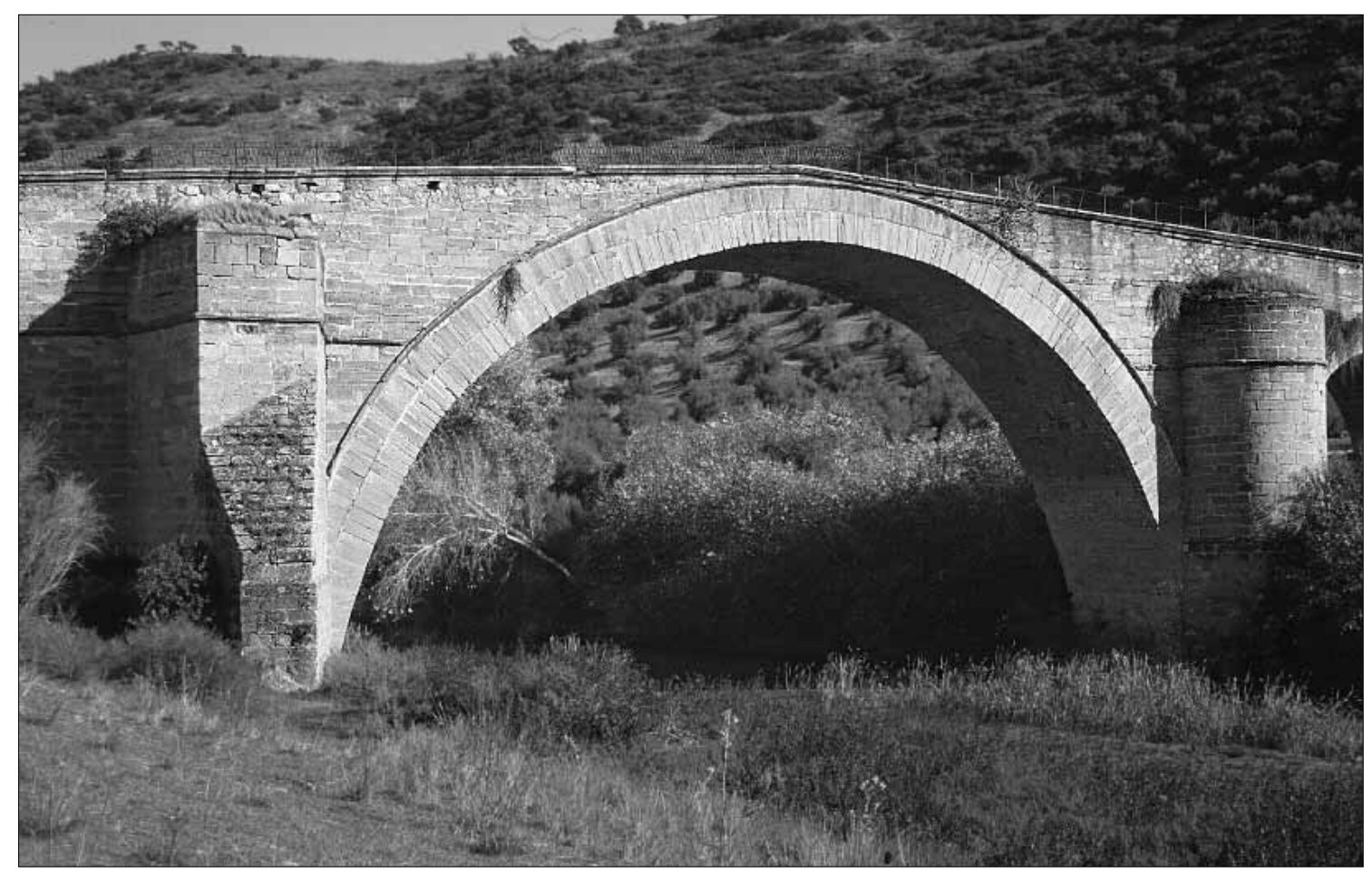

Fig. 3. Arco principal.

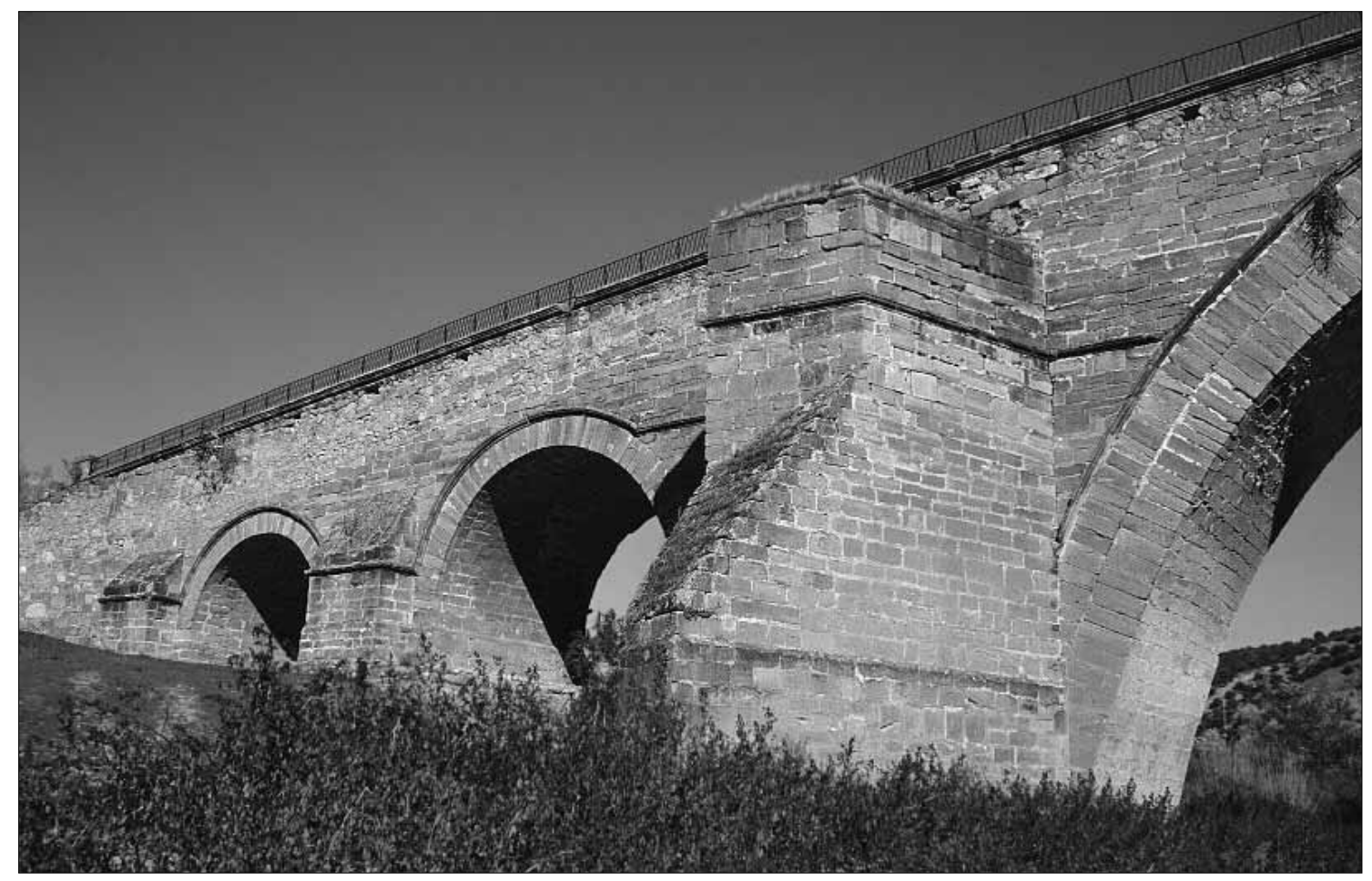

Fig. 4. Vista desde el Sudoeste. 


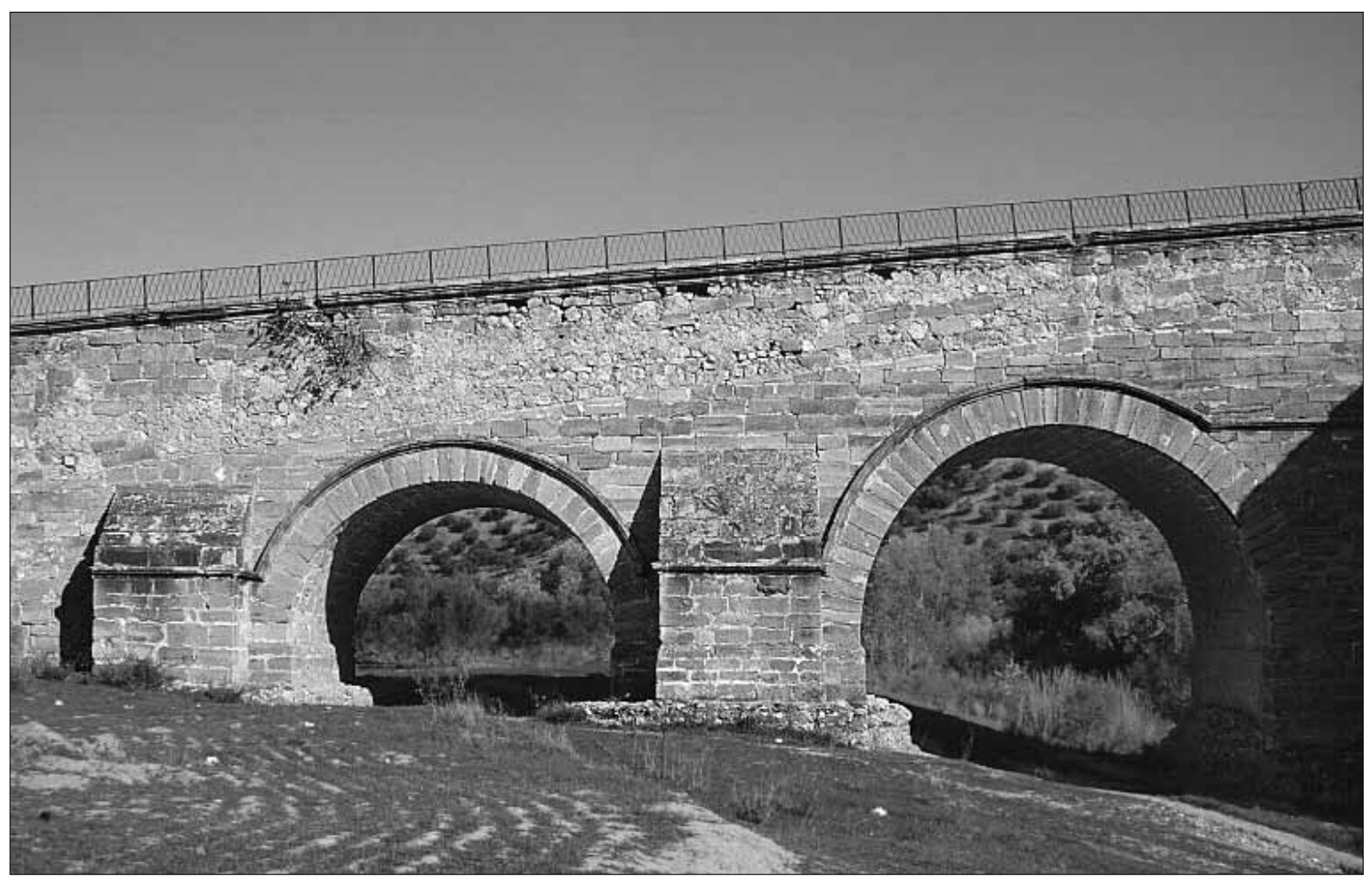

Fig. 5. Arcos situados al Norte.

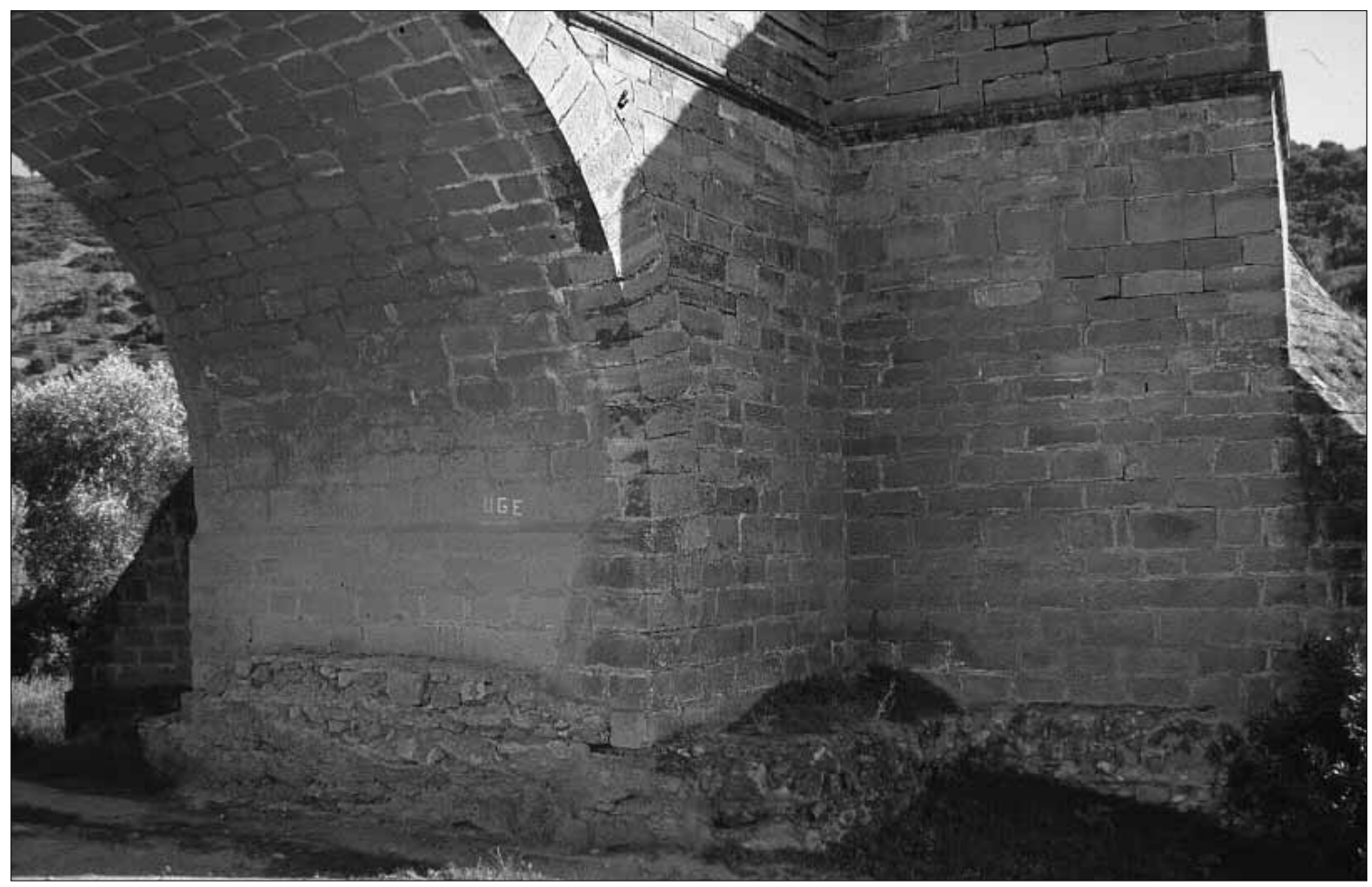

Fig. 6. Base del arco principal. 


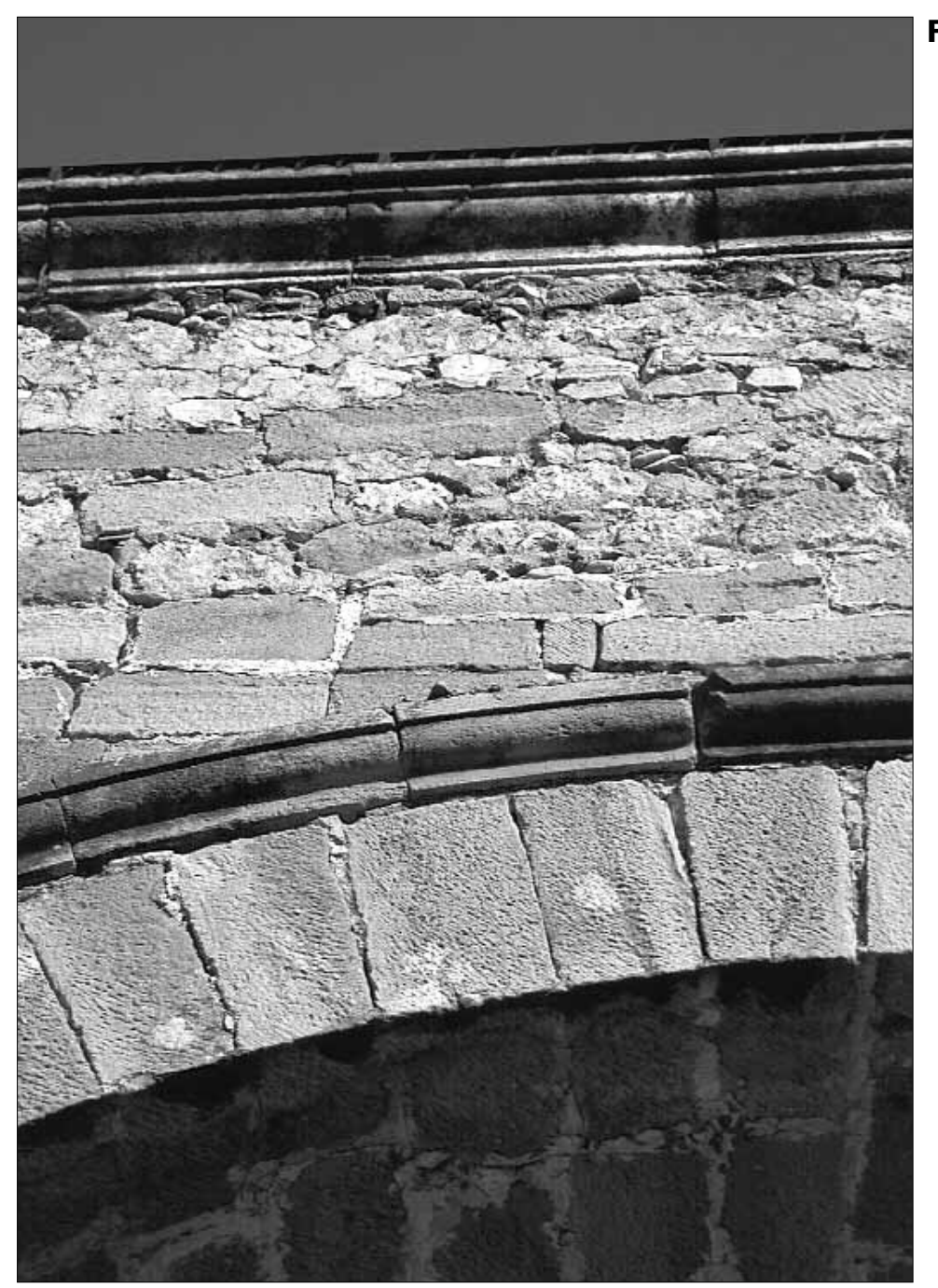

Fig. 7. Detalle del dovelaje.

Fig. 8. Detalle del aparejo.

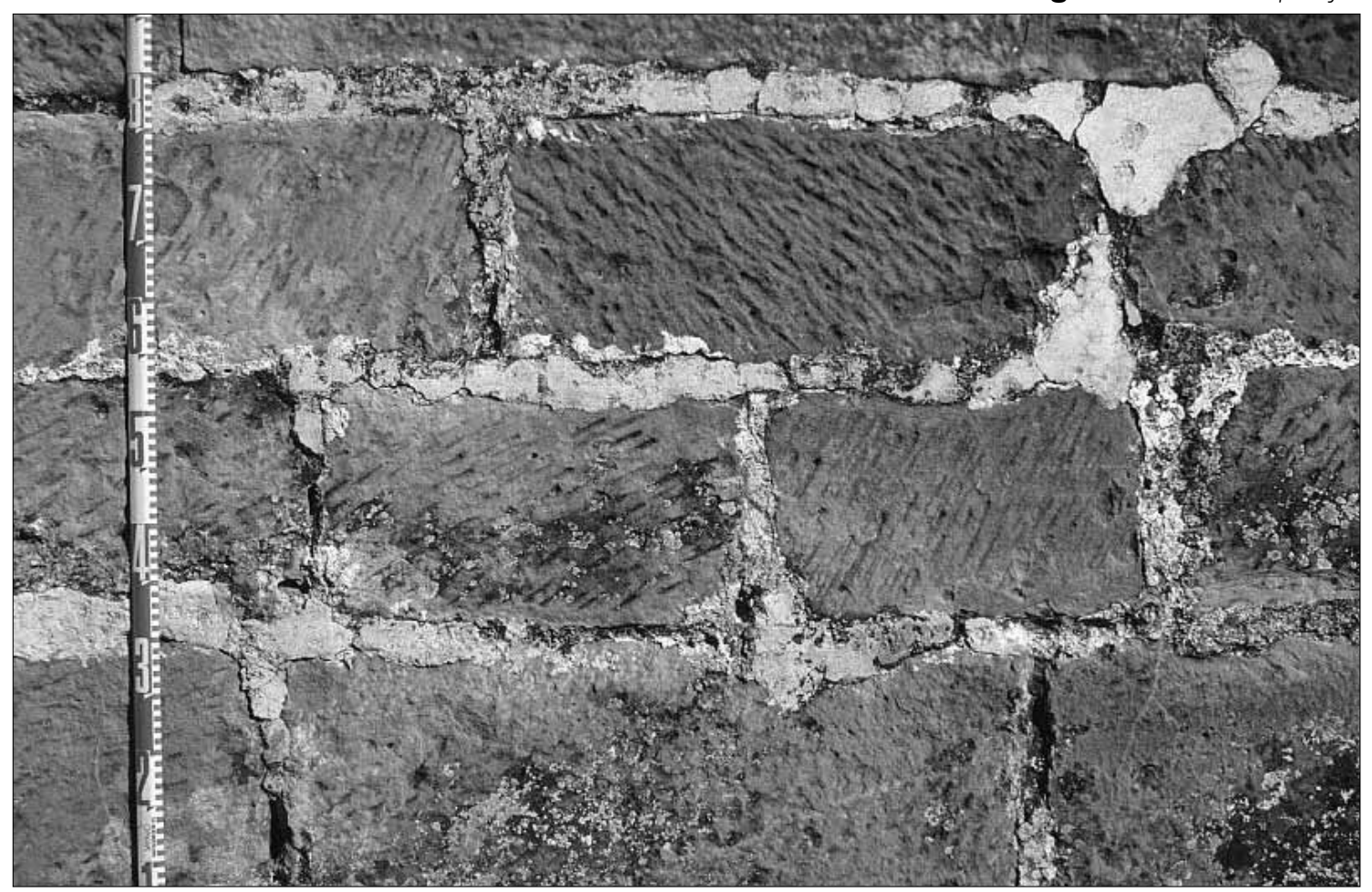

